Neuropsychobiology

\author{
Heinz Grunze \\ Jörg von Wegerer ${ }^{\mathrm{b}}$ \\ Robert W. Greene ${ }^{\mathrm{c}}$ \\ Jörg Walden ${ }^{\mathrm{b}}$ \\ a Psychiatrische Klinik der Universität, \\ München, und \\ ${ }^{\mathrm{b}}$ Universitätsklinik für Psychiatrie und \\ Psychosomatik, Freiburg, Germany; \\ c Harvard Medical School and \\ VAMC Brockton, Brockton Mass., USA
}

Neuropsychobiology 1998;38:131-138

\title{
Modulation of Calcium and Potassium Currents by Lamotrigine
}

\author{
Key Words \\ Lamotrigine \\ Calcium \\ Potassium \\ Carbamazepine \\ Valproate \\ Verapamil \\ Epilepsy \\ Bipolar disorder
}

\begin{abstract}
Actions of the new antiepileptic drug lamotrigine (LTG) were characterized using extracellular and whole cell patch clamp recordings from rat CA1 and CA3 pyramidal cells in vitro. The results suggest that LTG, beside its previously described effect on the fast sodium inward current, also modulates - presumably voltage-gated - calcium currents and the transient potassium outward current $I_{D}$. These may be effective mechanisms to inhibit pathological excitation in epilepsy and may be of potential benefit in treating underlying cellular disturbances in bipolar disorder.
\end{abstract}

\section{Introduction}

Lamotrigine (LTG; 3,5-diamino-6-(2,3 dichlorphenyl)1,2,4-triazine) is a clinically useful antiepileptic drug, mainly administered as an add-on medication to other anticonvulsants in therapy resistant epilepsy [1]. Due to reported efficacy in single case observations [2-4] it is also gaining increasing interest as a potential mood stabilizer in psychiatry. Similar to other antiepileptic drugs, e.g. carbamazepine (CBZ) and phenytoin, a blockade of voltage-dependent sodium channels [5] mainly in their inactivated state [6] has been demonstrated so far. Furthermore, LTG exerts cell-protective effects by decreasing glutamate release in the striatum [7]. Beside a high sodium influx and elevated glutamate release, an increase of the intracellular calcium concentration has been suggested as an underlying disturbance both in epilepsies and bipolar disorder [8]. Based on this rationale, calcium antagonists have been tested partially successfully for the treatment of bipolar disorder, both in manic and depressed episodes [9]. Another approach to limit hyperexcitability is a modulation of potassium currents. Recently, the important impact of potassium-dependent repolarization for age-specific epilepsies has been demonstrated [10]. The fast transient potassium outward current $\left(\mathrm{I}_{\mathrm{A}}\right)$ counteracts depolarization of a neuron. So far, an increase of this current has been demonstrated for valproate [11] and CBZ [12].

Most antiepileptic drugs which act on the level of ion channels do not exert just one specific blockade. For example, both valproate and CBZ show actions on voltage-gated sodium, calcium and potassium channels [12-15]. All of these excitation-limiting effects may be of potential value in treating both epilepsies and bipolar disorder. Our electrophysiological in vitro experiments were designed to test whether LTG is also capable of modulating calcium and potassium currents in hippocampal neurons beside its known action on sodium channels.

\begin{tabular}{ll}
\hline KARGER & C1998 S. Karger AG, Basel \\
Fax +41 61 306 12 34 & \\
$\begin{array}{l}\text { E-Mail karger@karger.ch } \\
\text { www.karger.ch }\end{array}$ & $\begin{array}{l}\text { Accessible online at: } \\
\text { http://BioMedNet.com/karger }\end{array}$
\end{tabular}

\footnotetext{
Heinz Grunze, MD

Psychiatrische Klinik der Universität

Nussbaumstrasse 7, D-80336 München (Germany)

Tel. +4989 51605335, Fax +498951605330

E-Mail grunze@psy.med.uni-muenchen.de
} 
Fig. 1. LTG reduces extracellular field potentials induced by omission of $\mathrm{Mg}^{2+}$ from the extracellular bath solution. Recordings before (baseline), $30 \mathrm{~min}$ during and $60 \mathrm{~min}$ after (wash-out) the superfusion with $20 \mu \mathrm{mol} / 1$ (A), $5 \mu \mathrm{mol} / 1$ (B) and $1 \mu \mathrm{mol} / 1 \mathrm{LTG}(\mathbf{C})$.
Fig. 2. Effects of combinations of subthreshold concentrations of LTG with subthreshold concentrations with $\mathrm{CBZ}(\mathbf{A})$, VERA (B) and 5-aminophosphonovalerate (APV; C).
$20 \mu \mathrm{mol} / \mathrm{l} \mathrm{LTG}$

A

baseline

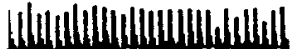

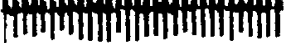

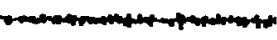

wash-out

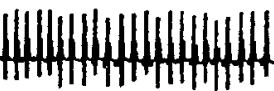

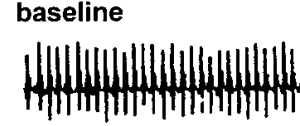

5 нmol/l LTG

B

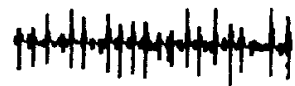

wash-out

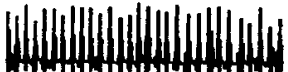

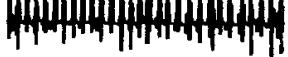

baseline

c $H+\ldots+n+\ldots+\ldots+\ldots+4+4$

wash-out

$1 \mu \mathrm{mol} / \mathrm{l} \mathrm{LTG}$

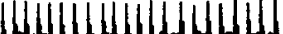

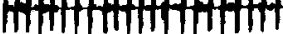

baseline

HHHAHHHHAH
$1 \mu \mathrm{mol} / / \mathrm{LTG}$
$+10 \mu \mathrm{mol} / / \mathrm{CBZ}$
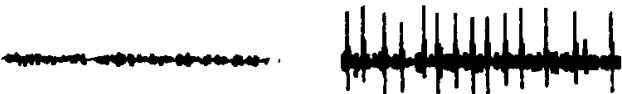

baseline

B
1 mol/I LTG +2 $\mu \mathrm{mol} / / \mathrm{l}$ Verapamil

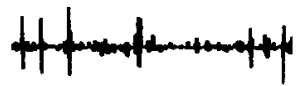

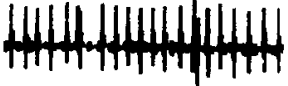

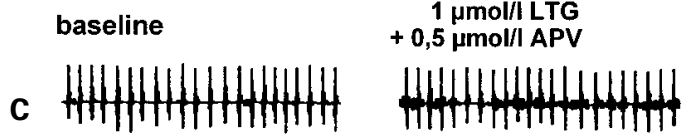

wash-out

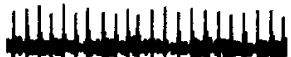

\section{Methods}

\section{Extracellular Recordings}

Extracellular recordings of spontaneous, rhythmic excitatory field potential (EFP) bursts in low $\mathrm{Mg}^{2+}$ artificial cerebrospinal fluid (ACSF) are a convenient method to screen substances for calcium antagonistic properties. Several investigations have shown that calcium currents essentially contribute to the generation of these EFPs [16, 17]. Reduction or omission of $\mathrm{Mg}^{2+}$ induces EFPs by increasing the transmembraneous calcium flux into the cell. Hitherto, suppression of EFPs indicates calcium antagonistic properties of a substance (for details of this rationale, see [17]).

Our experiments [18] were performed in hippocampal slices of guinea pigs (weight $350-550 \mathrm{~g}$, both genders). After removing the brain under ether anesthesia, transverse hippocampal slices of 350-500 $\mu M$ were cut. The ionic composition of the ACSF during pre-incubation of the slices for $1 \mathrm{~h}$ was (in mmol/l): $\mathrm{NaCl} 124, \mathrm{KCl}$
4, $\mathrm{CaCl}_{2}$ 0.75, $\mathrm{KH}_{2} \mathrm{PO}_{4} 1.24, \mathrm{MgCl}_{2} 1.3, \mathrm{NaHCO}_{3}$ 26, and glucose 10. Slices were kept at $28{ }^{\circ} \mathrm{C}$ and equilibrated with $5 \% \mathrm{CO}$ in $\mathrm{O}_{2}(\mathrm{pH}$ 7.35-7.4) throughout the preincubation and recording period. After placing a slice in the recording chamber and switching to ACSF without $\mathrm{Mg}^{2+}$, spontaneous EFPs developed in the hippocampal CA3 and CA1 area. To increase epileptic activity, potassium concentration was elevated from 4 to $8 \mathrm{mmol} / \mathrm{l}$ in some recordings. Recordings were made with borosilicate electrodes containing $2 \mathrm{mmol} / \mathrm{l} \mathrm{NaCl}$. The signals were amplified by a conventional microelectrode amplifier from NPI electronics, stored on an oscilloscope and plotted on a chart recorder. Results are given as mean $\pm \mathrm{SE}$.

\section{Intracellular Recordings}

In order to characterize the effect of LTG on the early transient potassium outward current, we performed whole cell patch clamp and voltage clamp recordings from CA 1 pyramidal neurons in a hippocampal slice preparation from Long-Evans rats (20-30 days, both genders). 
Harvesting of slices was done as described above. Slices were placed in a recording chamber continuously superfused with ACSF containing (in mmol/l): $\mathrm{NaCl} 124, \mathrm{KCl} 3.75, \mathrm{KH}_{2} \mathrm{PO}_{4} 1.25, \mathrm{MgCl}_{2} 1.3, \mathrm{CaCl}_{2} 2.5$, $\mathrm{NaHCO}_{3} 26$, glucose 10 . The ACSF was bubbled with $95 \% \mathrm{O}_{2} / 5 \% \mathrm{CO}_{2}$ and maintained at $30 \pm 2{ }^{\circ} \mathrm{C}$ throughout the recordings. The recordings were obtained with borosilicate glass electrodes (resistance 4-6 M $\Omega$ ) filled with (in mmol/l): K-citrate $120, \mathrm{CaCl}_{2} 1, \mathrm{MgCl}_{2} 3, \mathrm{MaATP} 2$, NaGTP 2, EGTA 3 and HEPES 40 (modified from Blanton et al. [19]). In voltage-clamp recordings, tetrodotoxin (TTX) $0.6 \mu \mathrm{mol} / \mathrm{lwas}$ added to the ACSF and in two experiments, tetraethylammonium chloride (TEA) $10 \mathrm{mmol} / 1$ was also added. LTG was dissolved in $0.3 \%$ DMSO (final concentration), which, in control experiments, had no effect on the electrophysiological properties, and was administered systemically with the ACSF. Both voltage clamp and current clamp recordings, using a bridge circuit, were made with an Axoclamp 2A amplifier (Axon Instruments, Burlingame, Calif., USA). Data were collected standardized at baseline, after a 30-min wash-in period of LTG and after a 30-min wash-out. Results are given in percent of change \pm SE.

Experiments were only conducted on cells with a resting membrane potential of $58 \mathrm{mV}$ and above (range in all cells considered for experiments $58-65 \mathrm{mV}$ ), their input resistance was between 50 and $100 \mathrm{M} \Omega$. These parameters were monitored for stability at the beginning and after a 30-min wash-out at the end of the experiment.

Differences in the species used and the composition of the ACSF are explained by the fact that extra- and intracellular recordings were conducted independently in two different laboratories. Drugs used were supplied from Sigma except for LTG (Glaxo-Wellcome, England) and CBZ (Desitin Arzneimittel GmbH, Germany).

\section{Results}

\section{Extracellular Recordings}

After switching the slice to a zero $\mathrm{Mg}^{2+}$ solution typical EFPs developed spontaneously within a few minutes (fig. 1, baseline) resembling the extracellular correlate of intracellular paroxysmal depolarization shifts $[13,14,20]$. The discharge rate of EFP in $8 \mathrm{mmol} / 1 \mathrm{~K}^{+}$in the ACSF was in the range of $21-88 / \mathrm{min}(\mathrm{n}=19)$ with no difference between the CA3 and CA1 region of the hippocampal slice [16].

When LTG $10 \mu \mathrm{mol} / \mathrm{l}$ was added, EFP were reduced both in amplitude and frequency up to a total suppression after 20-40 min. Typical experiments with 20,5 and $1 \mu \mathrm{mol} / 1 \mathrm{LTG}$ are depicted in figure 1 . A similar decline of EFP rates as with $20 \mu \mathrm{mol} / \mathrm{L} \mathrm{LTG}$ was observed in prior experiments where CBZ $(50 \mu \mathrm{mol} / 1)$ or verapamil (VERA, $20 \mu \mathrm{mol} / \mathrm{l}$ ) was added to the ACSF (cf. Walden et al. [13]). The effect of LTG on low- $\mathrm{Mg}^{2+}$-induced EFP showed dose-dependency with an EFP rate reduction for $5 \mu \mathrm{mol} / 1$ LTG to $0.22 \pm 0.24(n=5)$ and to $0.51 \pm 0.08(n=6)$ for $2 \mu \mathrm{mol} / 1 \mathrm{LTG}$. Following withdrawal of LTG from the ACSF, the baseline EFP rates were fully restored within $56-82 / \mathrm{min}$.

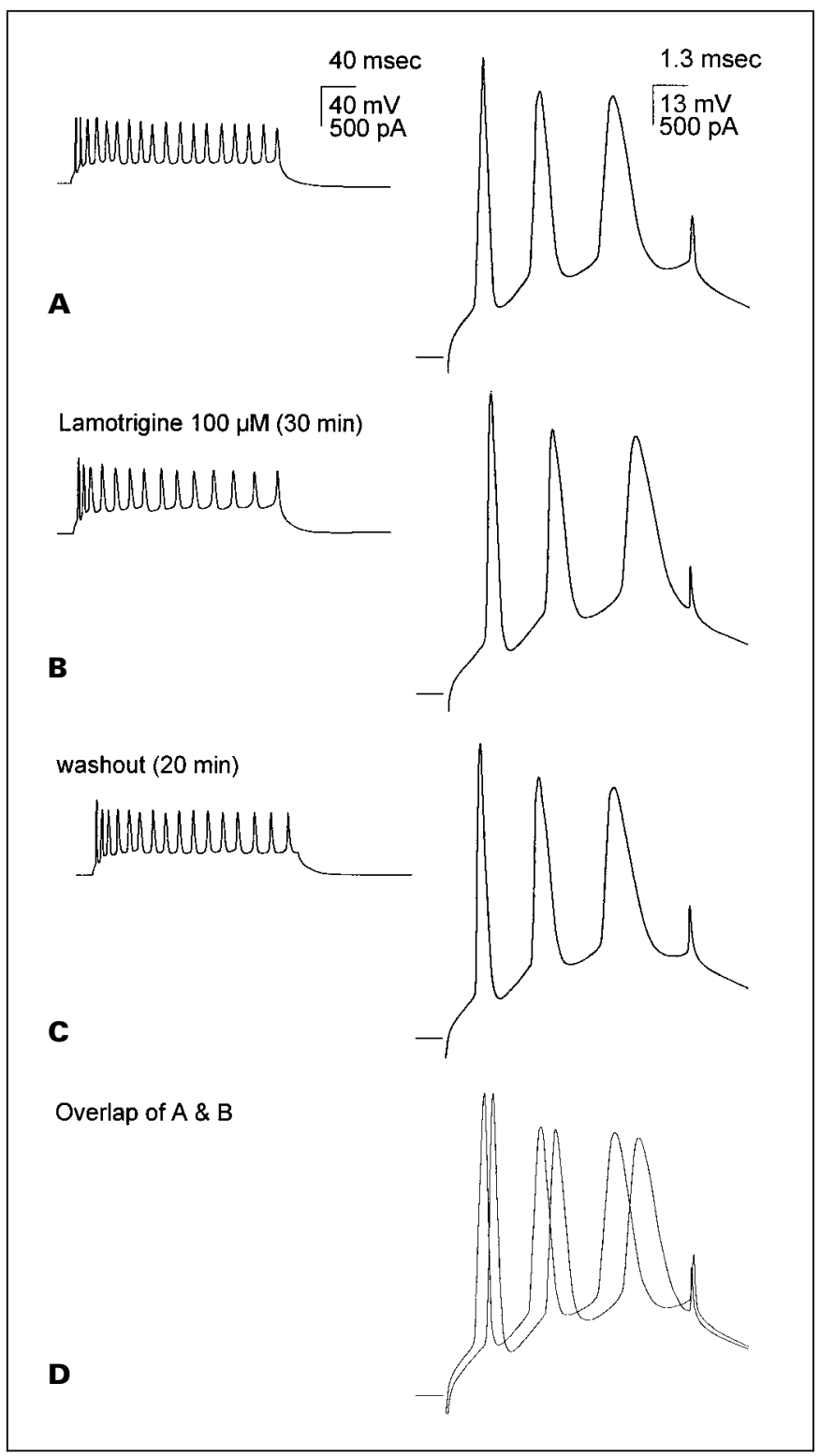

Fig. 3. $100 \mu M$ LTG reduces neuronal excitability in a whole cell patch clamp recording of a pyramidal CA1 neurone. Left trace: Response to $150 \mathrm{pA}$ current input, duration $250 \mathrm{~ms}$, holding potential $-60 \mathrm{mV}$. Right trace: Response to $850 \mathrm{pA}$ current input, duration $10 \mathrm{~ms}$, holding potential $-60 \mathrm{mV}$. A Baseline. B After 30-min LTG $(100 \mu M)$. C After 30 -min wash-out. D Overlap of $\mathbf{A}$ and $\mathbf{B}$, right traces.

With $1 \mu \mathrm{mol} / \mathrm{l} \mathrm{LTG}$, no effect on the EFP rate could be observed. This concentration of $1 \mu \mathrm{mol} / 1$ of LTG was considered as a subthreshold concentration (fig. 1C). Similar, subthreshold concentrations evaluated in earlier experiments were $2 \mu \mathrm{mol} / 1$ for VERA and $10 \mu \mathrm{mol} / 1$ for CBZ $[13,14]$. To investigate the additive effects of LTG

Neuropsychobiology 1998;38:131-138 
Fig. 4. Voltage clamp recordings, $100 \mu M$ LTG, TTX $0.6 \mu M$, HP $-80 \mathrm{mV}$. A Baseline response to depolarizing voltage steps of 10-40 mV. B After 30-min LTG. C Overlap of $\mathbf{A}$ and $\mathbf{B}$, response to a $+40 \mathrm{mV}$ step.

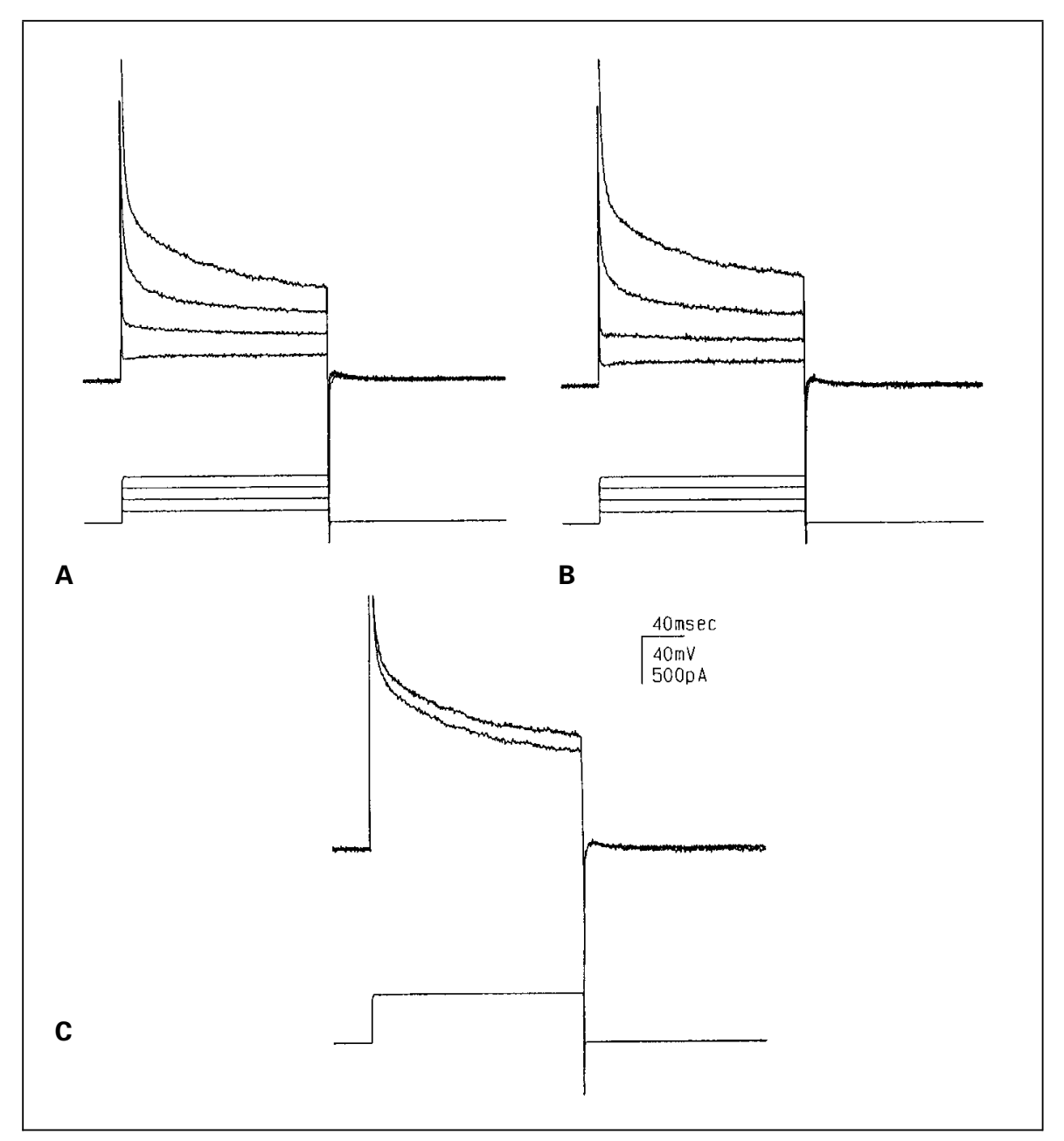

with CBZ and VERA, the subthreshold concentration of $1 \mu \mathrm{mol} / 1 \mathrm{LTG}$ was administered either with the subthreshold concentration of $10 \mu \mathrm{mol} / \mathrm{l} \mathrm{CBZ}$ or the subthreshold concentration of $2 \mu \mathrm{mol} / 1 \mathrm{VERA}$. These combinations reduced the EFP rate to $0.62 \pm 0.32(n=8)$ for $L T G$ with CBZ (fig. 2A) and to $0.34 \pm 0.14(n=6)$ for LTG with VERA (fig. 2B).

Since removal of the magnesium block of the postsynaptic NMDA receptor is one mechanism involved in the generation of low- $\mathrm{Mg}^{2+}$-induced field potential changes [17] the effect of the NMDA antagonist 5-aminophosphonovalerate (APV) on the EFP repetition rate was tested. APV reduced the frequency of occurrence of EFP in a dose-dependent manner. The subthreshold concentration of APV without effects on the EFP rate turned out to be $0.5 \mu \mathrm{mol} / 1$. However, combining subthreshold concentration of $1 \mu \mathrm{mol} / 1 \mathrm{LTG}$ with the subthreshold concentration of $0.5 \mu \mathrm{mol} / \mathrm{l} \mathrm{APV}$ was without effect $(\mathrm{n}=4$; fig. 2C), making the NMDA receptor unlikely as the primary site of action for LTG.

\section{Intracellular Recordings}

Bridge Mode Recordings. A depolarizing current was injected through the recording electrode (150-950 pA, $250 \mathrm{~ms}$ ), starting from a holding potential of $-60 \mathrm{mV}$, eliciting a high-frequency train of action potentials (AP). LTG $(25 \mu \mathrm{mol} / 1$, administered systemically with the ACSF for $30 \mathrm{~min}, \mathrm{n}=7$ ) neither effected input resistance, nor AP threshold and AP duration. Maximal spiking frequency at $150 \mathrm{pA}$ was reduced by $-36 \pm 27 \%$ (range $-67 \rightarrow 0 \%, \mathrm{p} \leq 0.025$, Mann-Whitney test). Although LTG had no effect on the AP amplitude of the first spike, it caused a nonsignificant trend of reversibly decreasing the AP amplitude of the second spike $(-5 \pm 6 \%)$. These findings can be explained with the previously described inhibition of fast sodium channels $[4,5,10]$. In $5 / 7$ cells, 
an increase of the latency from current input to AP threshold of the first spike $\left(\Delta_{\text {tc-tAP }}\right)$ was observed $(21 \pm 16 \%$, range $42 \rightarrow 0 \%$ ). All of these changes were only partially reversible within 30-min wash-out.

Increasing the concentration, LTG $(100 \mu \mathrm{mol} / 1, \mathrm{n}=6)$ diminished the first AP amplitude by $13 \pm 11 \%(\mathrm{p} \leq 0.025)$, and reduced the AP frequency for given current steps $(-43 \pm 20 \%$ at $350 \mathrm{pA},-42 \pm 9 \%$ at $150 \mathrm{pA}$, both significant at $\mathrm{p} \leq 0.025)$. Further analysis showed that this was caused by a reversible increase of the interspike interval with unchanged AP duration. $\Delta_{\text {tc-tAP }}$ was also increased by $55 \pm 37 \%(\mathrm{p} \leq 0.025)$ at $150 \mathrm{pA}$ (fig. 3$)$. This observation was backed up by 2 further recordings from a holding potential of $-75 \mathrm{mV}$ showing a clear-cut increase of $\Delta_{\text {tc-tAP }}$.

Voltage Clamp Recordings. These effects were a hint pointing towards a modulation of the fast transient potassium outward current. Accordingly, voltage clamp analysis was performed in 8 neurons after addition of TTX $(0.6 \mu \mathrm{mol} / 1)$. From a holding potential of $-80 \mathrm{mV}$, depolarizing voltage steps from 10 to $40 \mathrm{mV}$ were conducted. $6 / 8$ neurons showed an increase of a transient outward current, activated instantly and lasting for more than $200 \mathrm{~ms}$, observed with a step command of $+40 \mathrm{mV}$ in the presence of $100 \mu \mathrm{mol} / 1 \mathrm{LTG}$ (fig. 4). Again, this increase was only partially reversible within a 30-min washout period. To exclude an effect of DMSO by itself, three cells were recorded under similar conditions, adding only $0.3 \%$ DMSO. No changes were observed under this condition.

To ensure that this finding was not due to an increase of the delayed rectifier, we added TEA $10 \mathrm{mmol} / \mathrm{l}$ together with TTX at baseline ( $n=2$ neurons). As a result, we obtained a similar increase of the early current component which was again only partially reversible after a 30-min wash-out (fig. 5).

Analysis of all 8 neurons (fig. 6A) showed that this early current consists of an instantly activating and rapidly declining component (fig. 6B) and a second component, activated within a short delay and lasting for more than $150 \mathrm{~ms}$ (fig. 6C). This appears characteristic for $I_{A}$ and $I_{D}$, respectively [21]. These currents are closely related and co-existing fast transient potassium outward currents which are, in contrast to the delayed rectifier, not sensitive to TEA. Averaging over all 8 neurons and extrapolating to $\mathrm{t}=0$ showed an increase of current in LTG by 193 pA for the early component made of both $I_{A}$ and $I_{D}$. Subtracting the extrapolated $I_{D}$ component at $\mathrm{t}=0$, based on the current between 50 and $150 \mathrm{~ms}$ after $I_{A}$ inactivation, reveals that the current increase caused by LTG is almost exclusively due to an enhancement of

Lamotrigine Modulates Calcium and

Potassium Currents

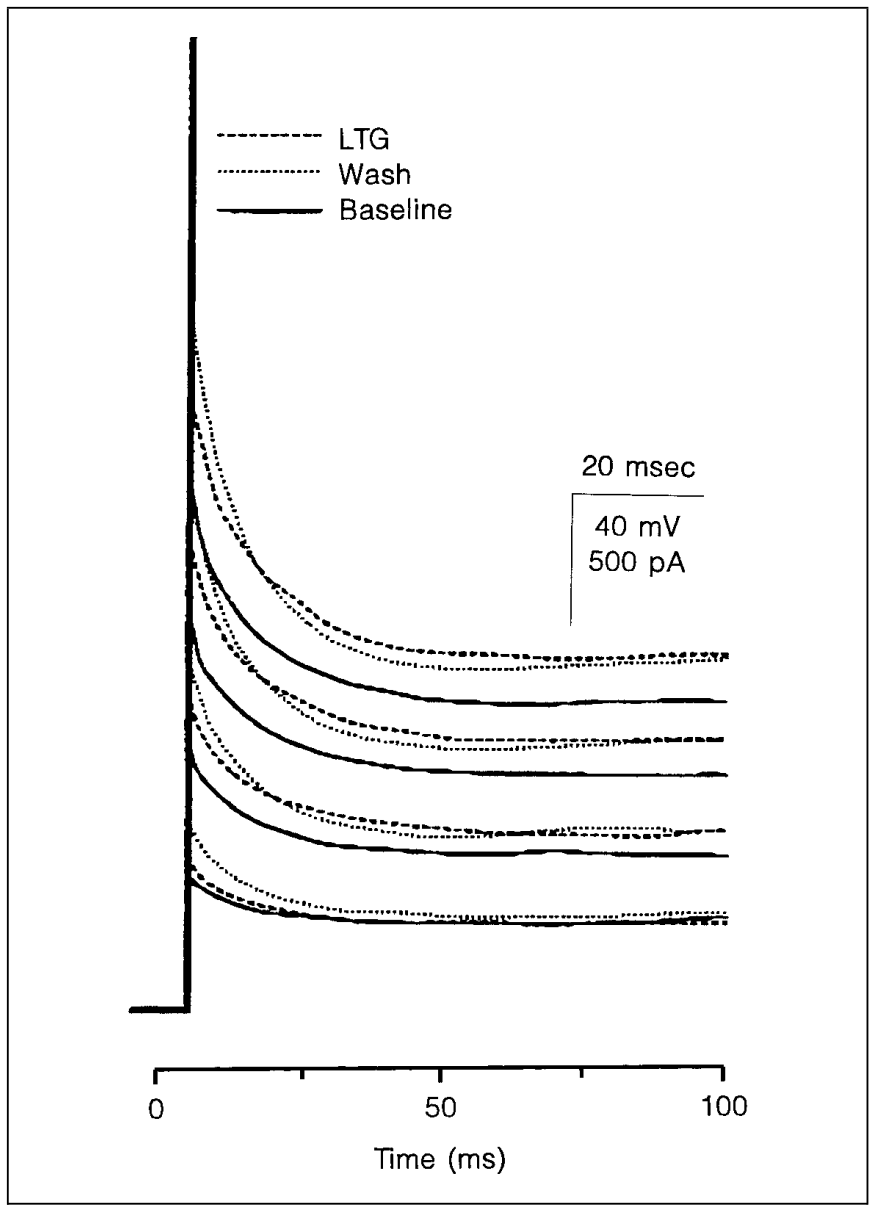

Fig. 5. Voltage clamp recordings, $100 \mu M$ LTG, TTX $0.6 \mu M$, TEA $10 \mathrm{mM}, \mathrm{HP}-80 \mathrm{mV}$. Magnification of the early components ( $\mathrm{t}$ from 0 to $100 \mathrm{~ms}$ ) shows again the increase of the fast, non-TEAsensitive transient outward current. Solid line = baseline; large dots = LTG for $20 \mathrm{~min}$; small dots = after a 30-min wash-out.

$I_{D}$ (fig. 6D). At this point, it remains undetermined whether this is a true increase or a shift of its steady state inactivation function, which still has to be further characterized.

\section{Discussion}

In the experiments presented here it was found that the new antiepileptic drug LTG reduced dose-dependently the repetition rate of extracellular field potentials in the low-magnesium model of epilepsy. The addition of subthreshold concentrations of LTG and the organic calcium antagonist VERA or the antiepileptic drug CBZ, respectively, also led to a reduction of the frequency of 
Fig. 6. A Plots of $\log I(p A)-t(m s)$ for the mean current of all 4 neurons in response to $\mathrm{a}+30 \mathrm{mV}$ step $(-80 \rightarrow-50 \mathrm{mV})$. I(BL $)=$ Control before LTG application; I(LTG) $=$ after 30 min application of $100 \mu M$ LTG. B Linear regression for the interval $10-40 \mathrm{~ms}$ to extrapolate for the $I_{A}$ component at $t=0$. C Linear regression for the interval $50-150 \mathrm{~ms}$ to extrapolate for the $I_{D}$ component at $t=0$. D Subtraction of the slow component $I_{D}$ from the fast component $\mathrm{I}_{\mathrm{A}}$ both for $\mathrm{LTG}$ and control reveals that there is no significant contribution of $I_{A}$. The overall increase of current is almost exclusively due to an increase of $I_{D}$.

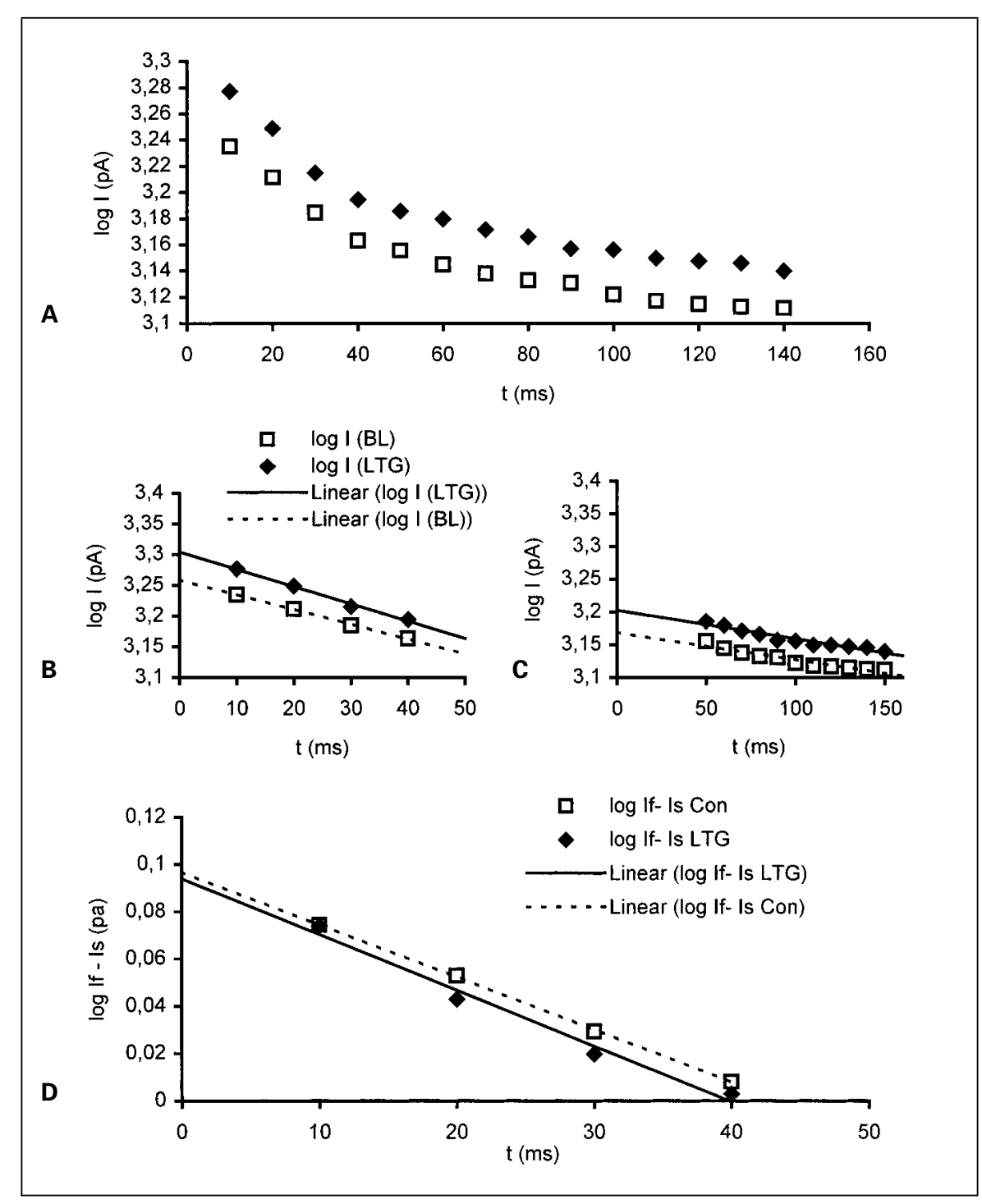

occurrence of zero- $\mathrm{Mg}^{2+}$-induced field potentials. The zero- $\mathrm{Mg}^{2+}$ model is thought to cause epileptiform discharges due to increased transmembraneous calcium ion fluxes and it is blocked by organic calcium channel inhibitors, e.g. VERA [13, 16, 22]. In concentrations as used in the present investigation, VERA specifically blocks Ltype calcium channels, but fails to alter other membrane currents nor affects glutamatergic or GABAergic neurotransmission [23-26]. Thus, LTG may beside its action on voltage-dependent sodium channels $[5,6]$ also modulate neuronal L-type calcium channels. This is of special interest because calcium antagonistic actions are discussed in treatment strategies of epilepsies [27] as well as in affective disorders [28].
Clinical effects of LTG require steady state plasma concentrations of about 4-16 $\mu \mathrm{mol} / 1$. However, some patients with epilepsy may need concentrations up to $40 \mu \mathrm{mol} / 1$ [29]. Because $55 \%$ of the total LTG in humans is bound to plasma proteins, the free concentration range is estimated between 2 and $20 \mu \mathrm{mol} / 1$ which corresponds to the concentrations used in the extracellular experiments. In intracellular experiments, higher concentrations $(100 \mu \mathrm{mol} / \mathrm{l})$ were used to obtain more pronounced differences of currents; however, the same direction, but not magnitude, of effects on potassium currents was also observed in clinically relevant concentrations of $25 \mu \mathrm{mol} / 1$. In this regard, most concentrations used in this in vitro model correspond to therapeutic plasma levels of LTG. 
These extracellular experiments do not differentiate between the types of calcium channels which may be blocked by LTG and the possibility cannot be ruled out that modulations of second messenger systems impinging on calcium channel phosphorylation may be involved. Moreover, the reports in the literature are controversial. Whereas Lees and Leach [30] describe the inhibitory effects of $100 \mu \mathrm{mol} / 1 \mathrm{LTG}$ on presumptive calcium currents in cultured cortical rat neurons, Lang and Wang [31] found no significant effect on L-type and T-type currents in whole cell clamped pituitary cell lines. For amygdala neurons, however, there are also recent reports on the effects of LTG on N-type calcium channels [32]. The additive effect of subthreshold concentrations of VERA and LTG in our experiments, however, also makes action via L-type calcium channels likely. Although presynaptic effects of LTG on NMDA channels have been described [33], actions through modulation of postsynaptic NMDA channels by LTG appear less likely, as it shows no additive effects in subthreshold concentrations with APV. Furthermore, it has been shown previously that LTG does not to exert actions on NMDA stimulated formation of cyclic GMP [5].

Intracellular recordings focused on another mechanism of limiting excitation, which is strengthening the fast potassium outward current. Our whole cell and voltage clamp experiments in hippocampal CA1 neurons suggest that LTG is a positive modulator of these currents. This is a property of LTG which was previously described for the inorganic substance zinc [34] and, for $I_{A}$, from two other antiepileptic drugs: valproate, tested in snail neurons [11] and CBZ, tested in neocortical cell cultures from rats [12], whereas, to our knowledge, positive modulators of $I_{D}$ have not been described yet.

In conclusion, our experiments show effects of LTG in a calcium-dependent model of epilepsy in extracellular recordings and on fast potassium outward currents in patch clamp recordings. This indicates that the therapeutic efficacy of this drug does not only result from its action on voltage-dependent sodium channels with the consequence of a decreased glutamate release, but also from other modulating effects on ion channels. With respect to calcium, this is of interest, since (a) a disturbed calcium ion homeostasis is discussed in the pathophysiology of affective disorders [8]; (b) the use of calcium antagonistic drugs is considered in the therapy of epilepsy [28], and (c) clinical studies with organic calcium antagonists have shown therapeutic effects both in mania and depression [35-38]. With respect to the modulation of potassium currents by LTG, similar results have been reported for valproate [11] and CBZ [12]; the implication of this finding for the pathophysiology and treatment of epilepsies or bipolar disorder, however, still has to be determined.

\section{References}

1 Messenheimer J: Lamotrigine. Epilepsia 1995; 36:S87-S94.

2 Walden J, Hesslinger B, van Calker D, Berger $\mathrm{M}$ : Addition of lamotrigine to valproate may enhance efficacy in the treatment of bipolar affective disorder. Pharmacopsychiatry 1996;29: 193-195.

3 Sporn A, Sachs G: The anticonvulsant lamotrigine in treatment resistant manic-depressive illness. J Clin Psychopharmacol 1997;17:185-189.

4 Calabrese J, Fatemi S, Woyshville M: Antidepressant effects of lamotrigine in rapid cycling bipolar disorder. Am J Psychiatry 1996;153:1236.

5 Leach M, Marden C, Miller A:Pharmacological studies on lamotrigine, a novel potential antiepileptic drug. II. Neurochemical studies on the mechanism of action. Epilepsia 1986;27:490-497.

6 Xie X, Lancaster B, Peakman T, Garthwaite J: Interaction of the antiepileptic drug lamotrigine with recombinant rat brain type IIA $\mathrm{Na}^{+}$channels and with native $\mathrm{Na}^{+}$channels in rat hippocampal neurones. Eur J Physiol 1995;430; $437-446$.
7 McGeer E, Zhu S: Lamotrigine protects against kainate but not ibotenate lesions in the rat striatum. Neurosci Lett 1990;112:348-351.

8 Grunze H, Kammerer C, Ackenheil M: The neurobiology of bipolar disorder. J Bipolar Disord 1997;1:2-12.

9 Dubovsky S, Buzan R: Novel alternatives and supplements to lithium and anticonvulsants for bipolar affective disorder. J Clin Psychiatry 1997;58:224-242.

10 Biervert C, Schroeder B, Kubisch C, Berkovic S, Propping P, Jentsch T, Steinlein O: A potassium channel mutation in neonatal human epilepsy. Science 1998;279:403-406.

11 Walden J, Altrup U, Reith H, Speckmann EJ: Effects of valproate on early and late potassium currents of single neurons. Eur Neuropsychopharmacol 1993;3:137-141.

12 Zona C, Tancredi V, Palma E, Pirrone G, Avoli M: Potassium currents in rat cortical neurons in culture are enhanced by the antiepileptic drug carbamazepine. Can J Physiol Pharmacol 1990; 68:545-547.
13 Walden J, Grunze H, Bingmann D, Liu Z, Düsing R: Calcium antagonistic effects of carbamazepine as a mechanism of action in neuropsychiatric disorders: Studies in calcium dependent model epilepsies. Eur Neuropsychopharmacol 1992;2:455-462.

14 Walden J, Grunze H, Mayer A, Düsing R, Schirrmacher K, Liu Z, Bingmann D: Calciumantagonistic effects of carbamazepine in epilepsies and affective psychoses. Neuropsychobiology 1993;27:171-175.

15 Meldrum B: Action of established and novel anticonvulsant drugs on the basic mechanisms of epilepsy. Epilepsy Res 1996;11:S67-S77.

16 Pohl M, Straub H, Speckmann E: Low-magnesium induced epileptic discharges in guinea pig hippocampal slices: Depression by the organic calcium antagonist verapamil. Brain Res 1986; 577:29-35. 
17 Grunze H, Walden J: Reduction of the frequency of occurrence of low magnesium induced field potentials in the hippocampus slice preparation of guinea pigs: A good screening tool for calcium antagonistic effects of anticonvulsant and antipsychotic drugs. Magnesium Res 1997;10:119-126.

18 Wegerer J, Hesslinger B, Berger M, Walden J: A calcium antagonistic effect of the new antiepileptic drug lamotrigine. Eur Neuropsychopharmacol 1997;7:77-81.

19 Blanton M, Lo Turco J, Kriegstein A: Whole cell recording from neurons in slices of reptilian and mammalian cerebral cortex. J Neurosci Methods 1989;30:203-210.

20 Mody I, Lambert JDC, Heinemann U: Low extracellular magnesium induces epileptiform activity and spreading depression in rat hippocampal slices. J Neurophysiol 1987;57:869888.

21 Storm J: Potassium currents in hippocampal pyramidal cells. Prog Brain Res 1990;83:161-187.

22 Straub H, Lück A, Köhling R, Moskopp D, Pohl M, Wassmann H, Speckmann E: Low magnesium induced epileptiform activity in the human neocortex maintained in vitro: Suppression by the organic calcium antagonist verapamil. J Epilepsy 1992;5:166-170.

23 Walden J, Pockberger H, Witte O, Speckmann E, Petsche H: Effects of organic calcium antagonists and agonists on invertebrate neurons; in Speckmann EJ, Schulze H, Walden J (eds): Epilepsy and Calcium. Munich, Urban \& Schwarzenberg, 1986, pp 257-276.
24 Bingmann D, Speckmann, E: Specific suppression of pentylene-tetrazol-induced epileptiform discharges in CA3 neurons (hippocampal slice, guinea pig) by the organic calcium antagonists flunarizine and verapamil. Exp Brain Res 1988; 74:239-248.

25 Lücke A, Speckmann E: Influence of the organic calcium antagonist verapamil on $\mathrm{N}$-methyl- $D$ aspartate (NMDA) induced cortical field potentials (neocortical slice, guinea pig). Neurosci Lett 1993;161:179-182.

26 Tappert U, Musshoff U, Madeja M, Lücke A, Speckmann E: Verapamil did not affect GABA and glutamate receptors. Eur J Physiol (Pflügers Arch) 1996;431:SR72.

27 Speckmann E, Schulze H, Walden J (eds): Epilepsy and Calcium. München, Urban \& Schwarzenberg, 1986.

28 Dubovsky S: Calcium antagonists in manic-depressive illness. Neuropsychobiology 1993;27: 184-192.

29 Peck A: Clinical pharmacology of lamotrigine. Epilepsia 1991;32:S9-S12.

30 Lees G, Leach M: Studies on the mechanism of action of the novel anticonvulsant lamotrigine (Lamictal) using primary neuroglial cultures from rat cortex. Brain Res 1993;612:190-199.

31 Lang D, Wang C: Lamotrigine and phenytoin interactions on ionic channels present in N4TG1 and GH3 clonal cells. Soc Neurosci Abstr 1991;17:1256.
32 Wang S, Huang C, Hsu K, Tsai J, Gean P: Inhibition of N-type calcium currents by lamotrigine in rat amygdalar neurones. Neuroreport 1996;7:3037-3040.

33 Wang S, Huang C, Hsu K, Tsai J, Gean P: Presynaptic inhibition of excitatory neurotransmission by lamotrigine in the rat amygdalar neurons. Synapse 1996;24:248-255.

34 Erdelyi L: Zinc modulates A-type potassium currents and neuronal excitability in snail neurons. Cell Mol Neurobiol 1994;14:689-700.

35 Brunet G, Cerlich B, Robert P, Dumas S, Souetre E, Darcourt G: Open trial of a calcium antagonist, nimodipine, in acute mania. Clin Neuropharmacol 1990;13:224-228.

36 Dubovsky SL: Calcium antagonists in manicdepressive illness. Neuropsychobiology 1993;27: 184-192.

37 Pazzaglia P, Post R, Ketter T, George M, Marangell L: Preliminary controlled trial of nimodipine in ultra-rapid cycling affective dysregulation. Psychiatr Res 1993;49:257-272.

38 Walden J, Fritze J, van Calker D, Berger M, Grunze H: A calcium antagonist for the treatment of depressive episodes: Single case reports. J Psychiatr Res 1995;29:71-76. 